\title{
Uma narrativa alternativa sobre a Baixada Fluminense: a experiência do Jornal da Baixada (1979-1980).
}

\author{
A alternative narrative about Baixada Fluminense: a experience of \\ Jornal da Baixada (1979-1980).
}

\author{
Alvaro de Oliveira Senra1 \\ Flávio Anício Andrade 2
}

\section{RESUMO}

Utilizando como fonte o Jornal da Baixada, publicado nos anos de 1979 e 1980, este artigo pretende discutir a emergência da luta por mel hores condições de vida na periferia da cidade do Rio de Janeiro, no contexto de reaparecimento na cena política de movimentos sociais demandantes do usufruto ao direito à cidadania em suas variadas formas. Ao mesmo tempo, ao tomar como sua fonte privilegiada um órgão da então chamada "imprensa alternativa" politicamente identificado com as lutas por direitos nos anos finais do governo militar instalado em 1964, se propõe abordar a construção de uma narrativa que assumiu intencionalmente o objetivo político de construir outra percepção identitária acerca da região socialmente definida como Baixada Fluminense, uma região tradicionalmente associada pela grande imprensa à violência, à carência de serviços públicos e às práticas políticas clientelistas.

Palavras-chave: Imprensa alternativa. Baixada Fluminense. Movimentos sociais.

\section{ABSTRACT}

Having the newspaper Jornal da Baixada as source, published in the years 1979 and 1980, this article discusses the emergence of the struggle for better living conditions on the outskirts of Rio de Janeiro, in the context of reappearance on the political scene of social movements that demands the right to citizenship in its various forms. At the same time, taking as its prime source a journalistic organ of the "alternative press", politically compromised with the struggles for rights in the final years of military government, this paper propose an analysis about the construction of a narrative that intentionally took the political goal of creation of another perception about the identity of the region socially defined like

1 Doutor em Ciências Sociais pela UERJ. Professor do Centro Federal de Educação Tecnológica Celso Suckow da Fonseca (CEFET-RJ). E-mail: alvarosenra@gmail.com

2 Doutor em Educação pela USP. Professor do Campus Nova Iguaçu da Universidade Federal Rural do Rio de Janeiro (UFRRJ). E-mail: flavioandrade.ufrrj@gmail.com 
"Baixada Fluminense", one region traditionally associated by the great press for its violence, the lack of public services and arcaic political practices.

Keyword: Alternative press. Baixada Fluminense. Social movements.

\section{Introdução}

Na passagem entre as décadas de 1970 e 1980, a imprensa noticiava os problemas da Baixada Fluminense sob um prisma que ressaltava uma região violenta, à margem da ação do Estado, sob controle de políticos personalistas e de milícias que impunham a ordem através da coerção pura e simples.

No entanto, a Baixada Fluminense vivia um rico período de lutas e mobilizações. Como em outras regiões do país, a Igreja Católica teve papel de destaque na organização e mobilização dos moradores, apoiando a constituição de associações de bairros, que formaram federações em diversos municípios. O sindicalismo renasceu, ganhando força em categorias presentes na região, como professores, metalúrgicos e petroleiros.

O Jornal da Baixada se propôs a construir de uma nova abordagem dos problemas da região, cuja solução dependeria da mobilização política de sujeitos sociais que ficavam à margem das decisões políticas, em mãos de grupos tradicionais que ocupavam o poder. Neste sentido, ao simultaneamente dar voz e ser sujeito político ativamente participante do movimento de ascensão das lutas populares por melhores condições de vida e trabalho na periferia metropolitana da cidade do Rio de Janeiro, o Jornal da Baixada se constitui em uma fonte relevante para a análise da ação política dos segmentos envolvidos na reorganização da sociedade civil no período histórico aqui abordado.

Buscamos, aqui, interpretar a memória daquele período, a partir de outra interpretação anterior, aquela dada pela narrativa do Jornal da Baixada. Sabemos que corremos riscos. Mas cremos que estes são pequenos, diante da possibilidade do risco maior que é o esquecimento daquela experiência.

Neste sentido, a memória do Jornal da Baixada não pode ser definida apenas como o registro de um pequeno jornal, que funcionou por um curto espaço de tempo, contando com o voluntariado de um grupo de militantes para ser idealizado, produzido e distribuído. Ela se confunde com uma época em que se apostava na mobilização popular para o enfrentamento de dificuldades que, atualmente, parecem ter desaparecido para sempre: quem pensa, nos dias de hoje, em recorrer a um deputado para uma simples vaga numa escola estadual? Há 
quanto tempo deixaram de existir os "roletões" nos ônibus, que não permitiam a passagem de pessoas obesas ou de mulheres grávidas? Ao mesmo tempo, denúncias e depoimentos publicados mostram que vários problemas se mantiveram, tornando penosa até hoje a vida dos cidadãos residentes na Baixada Fluminense, a exemplo da violência e da precariedade dos transportes públicos.

Para o Jornal da Baixada, era na organização, na mobilização e na luta que se buscava a criação de uma nova cultura política, tendo o povo como protagonista, capaz não somente de enfrentar esses e outros problemas, mas de criar um novo sentido de cidadania e uma nova narrativa sobre a região.

\section{A Baixada Fluminense como lugar geográfico e social}

A Baixada Fluminense, em termos de conceituação geográfica, constitui a região litorânea que se inicia no centro-sul do estado do Rio de Janeiro e se estende até a sua região nordeste, sendo constituída por vários municípios próximos à cidade do Rio de Janeiro, tendo como limites, além desta, as baías da Guanabara e de Sepetiba, e as montanhas da Serra do Mar.

Formada originalmente por terrenos alagadiços, que se alternam com pequenas elevações, além de áreas de mata atlântica e de manguezais, esta região foi predominantemente rural até a década de 1930. Constituía o entorno da então capital do país, uma área considerada insalubre e pontilhada por pequenas cidades e vilas ao longo dos caminhos, formando a passagem entre a cidade do Rio de Janeiro (cujo território compreendia o Município Neutro a partir do período regencial, e o Distrito Federal após a proclamação da República) e as regiões serranas que a separam do vale do rio Paraíba do Sul.

As trilhas para animais de carga e os rios, pequenos mas navegáveis, foram as formas de transporte de pessoas e mercadorias até a construção de ferrovias ligando a capital ao interior, na segunda metade do século XIX, fato que possibilitou o aumento de sua população, assim como o desenvolvimento de uma agricultura comercial, baseada principalmente na citricultura.

Na década de 1930 foram realizadas obras de drenagem nas bacias hidrográficas do Iguaçu/Sarapuí e Pavuna/Meriti, rios que cortam a região, permitindo a ampliação dos terrenos ocupáveis e a construção de vias de transporte terrestre. O saneamento da Baixada Fluminense e a sua localização, na saída do Rio de Janeiro em direção a São Paulo, principais 
áreas urbanas do país, foram dessa forma, elementos que propiciaram um rápido crescimento econômico e populacional da região.

No entanto, a partir justamente da ocupação da porção mais próxima da cidade do Rio de Janeiro em meados do século XX, a Baixada Fluminense passou a constituir um espaço social mais particular no qual avançavam as áreas urbanas ou em processo de urbanização que se formaram ao longo das ferrovias e da Via Dutra, rodovia inaugurada em 1951 a fim de ligar as mencionadas áreas metropolitanas do Rio de Janeiro e São Paulo. Foi inclusive a construção desta rodovia que deu o impulso definitivo para a ocupação mais acelerada desta área particular da região, tendo como centro urbano mais importante a cidade de Nova Iguaçu.

Naquele período a Baixada Fluminense passou gradativamente da condição de área de economia rural para a de periferia urbana. A construção dos ramais ferroviários e o loteamento de grandes parcelas de terra, principalmente nos municípios de Nova Iguaçu e de Duque de Caxias (que se emancipou do primeiro em 1943), atraíram milhares de trabalhadores saídos da cidade do Rio de Janeiro e imigrantes vindos de outras regiões, que ali se fixaram pela possibilidade de compra de terrenos a preços mais acessíveis e pela existência das vias de transporte para a capital federal.

O crescimento populacional da região foi extremamente rápido. Nova Iguaçu, então o principal município da Baixada Fluminense, possuía em 1920 um total de 33.396 habitantes, número que atingiu a 145.649 em 1950; vinte anos depois esse montante chegava a 727.140. (MAINWARING, 1989, p. 209).

Isso fez desse mesmo município o que apresentou o mais rápido crescimento entre os de maior população do país. E se naquele mesmo ano de 1950 quase a metade da sua população residia na área rural (46,6\%), em 1980 esta porcentagem caiu para apenas $0,29 \%$. Ainda em 1980, Nova Iguaçu havia se transformado na sétima maior cidade do país em número de habitantes com um total de 1.094 .805 pessoas vivendo no seu território. (MAINWARING, 1989, p. 209).

Esse aumento populacional adquire ainda mais relevo, porque coincidiu com a perda de grande parte do território original do município. Da área original de Nova Iguaçu se emancipou, inicialmente, o município de Duque de Caxias. Os outros municípios da área urbana principal da Baixada Fluminense (Nilópolis, São João de Meriti, Queimados. Belford Roxo e Mesquita) seriam resultado de desmembramentos territoriais posteriores de Nova Iguaçu e Duque de Caxias.

A partir das décadas intermediárias do século XX ocorreu crescimento populacional acelerado em todas as cidades da Baixada Fluminense, com a evidente constatação de que o 
aumento populacional não foi acompanhado de uma adequada urbanização e da expansão de serviços urbanos essenciais, como saneamento, transporte público, educação e saúde.

O processo de rápida ocupação populacional da região coincidiu historicamente com o período em que o Estado brasileiro tomou para si a iniciativa de promover a industrialização, vista como condição necessária para o advento da modernidade nacional. A Baixada Fluminense foi o terreno da implantação de gra ndes empreendimentos industriais estatais, como a Fábrica Nacional de Motores (FNM), implantada em 1942 no Distrito de Xerém (que no ano seguinte faria parte de Duque de Caxias), criada para produzir motores de avião e que, posteriormente, se destacou pela montagem de caminhões pesados em parceria com a empresa italiana Alfa Romeo. A FNM foi privatizada em 1977 e encerrou suas atividades em 1985.

Outra estatal, a PETROBRAS, inaugurou em 1961 a Refinaria Duque de Caxias (REDUC), no município de mesmo nome. Além da FNM e da REDUC, um grande número de indústrias privadas, como químicas e metalúrgicas de grande porte, empresas alimentícias e de transportes e um sem-número de pequenas empresas, deram à região uma importância econômica considerável.

A despeito da proximidade e das fortes ligações econômicas com a cidade do Rio de Janeiro, até a fusão em 1975 (quando a cidade do Rio de Janeiro deixou de ser o estado da Guanabara), a Baixada Fluminense pertencia politicamente ao estado do Rio de Janeiro, desvinculada administrativamente do Distrito Federal e, posteriormente ao ano de 1960, do estado da Guanabara.

No entanto, apesar do grande peso econômico, a ideia de Baixada Fluminense remetia (e ainda remete) principalmente à sua condição periférica e de região dependente da metrópole do Rio de Janeiro. Diariamente, milhares de trabalhadores e estudantes se deslocam entre os municípios da Baixada e aquela cidade, através de transporte rodoviário e ferroviário. Além disso, a ideia de periferia remete às mazelas que dela derivam: pobreza, precariedade dos serviços urbanos, clientelismo e personalismo político e, talvez aquela que seja a imagem mais difundida, a violência.

A violência, nesse caso, não se referia somente aos riscos permanentes que envolviam os habitantes da região e seus bens; ela abarcou a própria esfera política institucional, simbolizada na figura de Tenório Cavalcanti (1906-1987), parlamentar com forte base eleitoral no município de Duque de Caxias, que se utilizava, contra seus adversários, de métodos que incluíam muitas vezes o uso da intimidação e da pistolagem.

A violência era (e continua a ser) um dado real da vida cotidiana, e teve como complemento a truculência da ação policial, acrescida da atuação de grupos paramilitares ou de extermínio, principalmente ao longo dos governos militares (1964-1985): duas mil pessoas 
foram assassinadas até 1979, em Nova Iguaçu, pela organização conhecida como Esquadrão da Morte. Somente no primeiro semestre de 1980, outras 764 foram executadas por este e outros grupos no mesmo município. (MAINWARING, 1989, p. 211).

A narrativa da imprensa sobre a região espelhou todo esse conjunto de problemas, contribuindo para fixar uma imagem que, embora tivesse profundas raízes na realidade, não deixava de ser parcial: por exemplo, deixava-se em segundo plano a existência de setores econômicos e sociais pujantes, de ricas experiências culturais e de tradições políticas que se construíram às margens das práticas costumeiras de clientelismo e personalismo.

\section{A imprensa e a construção da imagem da Baixada Fluminense}

No período abarcado por este artigo, a cidade do Rio de Janeiro sediava jornais de grande importância para o país, como O Globo e o Jornal do Brasil, prioritariamente voltados para temáticas políticas e econômicas de natureza nacional, ou então mais atentos para as questões da própria cidade, dando pouca relevância aos problemas da Baixada Fluminense ou de outras regiões do interior do estado. Outros jornais, com ênfase mais regional, possuíam grande circulação na passagem entre as décadas de 1970 e 1980 . Este era o caso de Última Hora e de $O$ Dia, com público mais popular, que além da abordagem sobre problemas econômicos de impacto na vida cotidiana, crimes e esportes, davam destaque às mazelas sociais da Baixada Fluminense, contribuindo para a criação de referências que consolidaram a sua imagem social. A Luta Democrática, jornal de propriedade do citado deputado Tenório Cavalcanti, também manteve a linha de caracterizar a região como uma terra sem lei.

De baixo custo e com grande número de leitores nas classes populares, esses três últimos diários exploraram a violência na região para garantir o aumento de suas tiragens, inclusive com largo apelo a títulos e fotos chocantes, o que reforçou a idéia de que na Baixada Fluminense a vida cotidiana era entremeada pela violência. Os outros problemas e aspectos da vida urbana da região tinham abordagem secundária, e praticamente se ignoravam conteúdos que relacionassem a Baixada Fluminense a atividades culturais ou pautas de comportamento. (ENNE, 2004).

Somente a partir da década de 1990 é que esta visão se transformaria de forma parcial e gradual. Muitos dos problemas existentes e difundidos pelos meios de comunicação se mantiveram, mas passaram a conviver com transformações decorrentes de um maior desenvolvimento econômico da região, do fortalecimento dos movimentos sociais e 
culturais, assim como da eleição, em alguns municípios, de prefeitos vinculados a correntes políticas de oposição às lideranças tradicionais, com práticas renovadoras que fortaleceram a participação política da população. Ao mesmo tempo, a partir da última década do século XX, os jornais de maior circulação no Rio de Janeiro, como os já citados $O$ Globo e $O$ Dia, passaram a dedicar mais visibilidade à Baixada Fluminense, inclusive criando suplementos específicos dedicados à economia e à vida cultural. (ENNE, 2004).

Entretanto, no tempo de atuação do Jornal da Baixada e, de forma mais ampla, no período abordado neste artigo, a violência, a carência de serviços públicos e as práticas políticas clientelistas, como já afirmado anteriormente, dominavam o noticiário e construíram o imaginário social sobre a região. Os pequenos jornais municipais repetiam o modelo tradicional de promoção de práticas, grupos e indivíduos vinculados às elites locais, tendo pouca repercussão, a não ser em períodos de maior tensão política e/ou eleitoral, através de denúncias contra opositores ou promoção de seus candidatos.

Nesta direção, a imprensa tendeu a desconsiderar a trajetória de reivindicação e contestação presente na história da Baixada Fluminense, exemplificada por diversos episódios e movimentos, como as revoltas populares de 1962, com saques de mercados, em protesto contra a carestia e a escassez de alimentos básicos; as ações sindicais ocorridas antes de 1964; as lutas dos posseiros pela permanência em suas terras, nas áreas que mantiveram a economia rural; a mobilização da sociedade civil pela recuperação da autonomia política de Duque de Caxias, importante município da região, transformado em área de segurança nacional por decisão do Regime Militar; ou ainda os grandes movimentos grevistas ocorridos no final da década de 1970, envolvendo professores e metalúrgicos, entre outras categorias profissionais. (ENNE, 2004).

Além disso, a região tem um histórico de organizações de caráter associativo ou reivindicatório, contestando as práticas políticas tradicionais. Nos últimos anos do período democrático entre o fim do Estado Novo (1945) e os governos militares pós-1964, espalharam-se, principalmente em Nova Iguaçu, Associações e Centros Pró-Melhoramentos de Bairros. Em 1960, esses grupos chegaram a realizar um Congresso dos Centros PróMelhoramentos de Nova Iguaçu, que reuniu várias associações de bairro e obteve algumas concessões da Prefeitura. $O$ partido que esteve à frente da maioria desses movimentos foi o Partido Comunista Brasileiro (PCB). (SILVA, 1993, p. 27).

A partir da segunda metade da década de 1970 a Baixada Fluminense foi palco de grandes mobilizações populares e de trabalhadores, inserindo-se no processo de revitalização dos movimentos sociais que atingiu várias partes do país, acelerando o fim do Regime Militar e dando conteúdo social ao processo de redemocratização.

As ações de ativistas ligados à Igreja Católica, com incentivo da Diocese de Nova Iguaçu, encabeçada de 1966 a 1995 por D. Adriano Hypólito, bispo identificado com o catolicismo 
progressista, além da presença de correntes de esquerda que investiam na organização popular, contribuíram para a criação e difusão de movimentos sociais, estabelecendo um contraponto à política tradicional da região, ora vinculada às forças políticas identificadas com o Regime Militar, ora pertencente às estruturas locais do Movimento Democrático Brasileiro (MDB), dominadas pelo grupo do governador Chagas Freitas, que ocupou o Executivo estadual entre 1979 e 1983, de natureza conservadora e pouco afeito à aproximação com movimentos populares. 3

A partir de 1978, iniciativas de coordenação das experiências associativas locais de moradores foram realizadas, culminando na fundação de Federações de Associações de Moradores em vários municípios, das quais uma das mais mobilizadas e importantes foi o Movimento de Amigos de Bairros de Nova Iguaçu. O MAB promoveu grandes mobilizações a partir de reivindicações que iam do transporte público ao saneamento básico, da abertura de canais de participação popular ao aumento de vagas nas escolas. Em 1979 o MAB patrocinou a formação de uma Comissão Geral dos Conjuntos para lutar contra o despejo dos morador es dos conjuntos residenciais do Banco Nacional da Habitação (BNH), que viviam pressionados pelo aumento das prestações e constantemente ameaçados de expulsão. Naquele ano o BNH tinha financiado a construção de 23 destes conjuntos na Baixada Fluminense, e, somente em 1979, 3.500 processos de despejo estavam em andamento no Fórum de Nova Iguaçu. (SILVA, 1993, p. 81).

Todas essas lutas, os agentes que delas participaram, e os moradores e trabalhadores da região tiveram no Jornal da Baixada um canal de expressão. Editado no município de São João de Meriti nos anos de 1979 e 1980, se propôs a uma abordagem alternativa dos problemas da Baixada Fluminense, dando voz aos movimentos sindicais e populares que atuavam em municípios da região, além de apoiar e exercer funções de organização política no contexto do processo de renascimento dos movimentos sindical e popular nos anos finais da década de 1970.

Sem negar, em nenhum momento, as difíceis condições de vida dos cidadãos da Baixada Fluminense, o Jornal da Baixada construiu uma narrativa que valorizou aquilo que a imprensa não priorizava: a possibilidade de transformação da região como resultado da mobilização e da ação política dos próprios moradores e trabalhadores.

Em sua primeira edição, datada de 15 de maio de 1979, o Jornal apresentava-se da seguinte maneira à população, definindo desde já sua linha editorial:

POBRE, ATREVIDO, INDEPENDENTE - O JORNAL DA BAIXADA nasce do esforço dos moradores e trabalhadores da Baixada e conta com a

3 Anteriormente à fusão, já Chagas Freitas já havia governado o estado da Guanabara de 1971 a 1975. 
colaboração de um grupo de jornalistas. O Jornal da Baixada quer estar junto das associações de bairro, dos sindicatos de trabalhadores e de outras entidades da região para transmitir suas opiniões, levantar suas reivindicações, exigir soluções. É mais um instrumento de luta pela melhoria das condições de vida do povo. [...] O Jornal da Baixada nasce para viver a vida do povo da Baixada Fluminense. (JORNAL DA BAIXADA, n. 1, maio de 1979, p. 2)

O Jornal da Baixada, dessa forma, cumpriu primeiramente um papel de se apresentar como espaço de divulgação e amplificação das reivindicações que irromperam na região por melhores condições de trabalho, pela posse da terra, além das mobilizações relacionadas às condições de moradia, transporte, segurança, saúde e educação.

A existência do Jornal que constitui a fonte de pesquisa deste artigo se situa em um contexto de proliferação de diversos periódicos que constituíram a chamada "imprensa alternativa".

Embora já existisse no Brasil uma imprensa crítica ou à margem das correntes principais da "grande imprensa" há várias décadas, foi a partir de 1964 que se estabeleceu um padrão oposicionista que definiu os jornais alternativos. O Pasquim talvez tenha sido o maior exemplo de um jornal alternativo de humor e cultura que conseguiu se dotar de um esquema profissional de produção e distribuição, mesmo circulando nos períodos mais duros do Regime Militar.

O afrouxamento da censura e a relativa liberalização da atividade política a partir do governo do general Ernesto Geisel (1974-1979) permitiram que jornais vinculados a correntes políticas clandestinas ou semiclandestinas, ou, então, dedicados a temáticas específicas que despontavam naqueles anos (a luta contra o racismo, o movimento ambientalista, o feminismo ou o direito à opção sexual) começassem a ser publicados. (GENTILI, 2008, p. 304)

O Jornal da Baixada também foi idealizado a partir de uma das correntes políticas de esquerda atuantes naquele período, a Ala Vermelha, oriunda de uma dissidência do Partido Comunista do Brasil (PCdoB). Entre os anos de 1971 e 1974, essa corrente abandonou a perspectiva da luta armada e passou a investir na organização popular, inclusive deslocando militantes de outras áreas do Rio de Janeiro para a Baixada Fluminense, onde eles passaram a viver e a militar. Sua estratégia incluía a atuação junto a sindicatos de várias categorias e a associações de moradores, assim como a organização de centros culturais e do próprio Jornal (RIBEIRO, 2011). 
O Jornal, no entanto, não se organizou apenas em torno dos militantes daquela corrente de esquerda, atraindo indivíduos independentes. A partir de 1980, a maioria dos participantes do Jornal se envolveu na criação de diretórios do Partido dos Trabalhadores em vários municípios da região. ${ }^{4}$

Como regra, a imprensa alternativa (como ficou usualmente conhecida) era formada por jornais estruturados em torno de esquemas de produção e distribuição militantes e voluntários, sendo distribuídos principalmente em locais públicos.

O Jornal da Baixada, embora também fosse vendido em bancas e busca sse o patrocínio de pequenos comerciantes, não fugiu a tal regra. No entanto, ao enfatizar principalmente problemas locais, abria um certo distanciamento do típico órgão alternativo dedicado a temáticas políticas de cunho nacional.

Além da denúncia das dificuldades da vida cotidiana e da visibilidade e da voz concedidas aos movimentos sociais e aos moradores da Baixada Fluminense, o Jornal procurou atuar como articulador entre os movimentos populares de moradores, os sindicatos de trabalhadores e as lutas pela terra que ocorriam nas áreas rurais da região.

A título de exemplo, a quarta edição do jornal, editada em agosto de 1979, abriu grande espaço às queixas dos moradores com a carestia. As taxas de inflação vinham crescendo desde meados da década, e atingiram 44,8\% em 1977, 40,8\% em 1978, chegando a $77,2 \%$ no ano de 1979, sem que houvesse mecanismos de reposição total das perdas salariais. (ALVES, 1984, p. 331).

A posição adotada por Murilo Macedo, Ministro do Trabalho do governo do general João Figueiredo (1974-1979), impunha a contenção salarial como forma de evitar um aumento ainda maior da inflação, causando graves problemas para os trabalhadores e fazendo explodir greves e protestos em todo o país. Somente em 1979 foram registradas 68 greves no Rio de Janeiro, e um total de 430 em todo o país (BADARÓ, 1988, p. 241).

Os moradores entrevistados pelo Jornal apontavam, em comum, a falta de dinheiro para adquirir os bens necessários a uma vida digna. Nas palavras de Dona Maria Aparecida Feital Ramos, moradora de Mesquita (hoje município, então bairro de Nova Iguaçu):

O dinheiro não dá para fazer compra mensal. No final do mês nós pedimos dinheiro emprestado. $\mathrm{E}$ quando a gente recebe tem que pagar, e aí fica sempre pedindo emprestado. Eu pago 478,00 cruzeiros de prestação pela televisão. A geladeira custa 318,00 cruzeiros por mês.

4 Sobre o conjunto da esquerda brasileira na década de 1970: Ridenti (2010). 
Gasto dois botijões de gás por mês (300,00 cruzeiros) e pago 430,00 cruzeiros de luz e 350,00 cruzeiros de água por trimestre. [...] Fruta não entra na minha casa nem quando eu recebo salário. Só abacate quando está no tempo porque minha vizinha me dá. O que eu como quase todo dia é arroz, feijão e ovo [...]. (JORNAL DA BAIXADA , n.4, outubro de 1979, p. 4)

Este e outros depoimentos espelham as consequências da carestia no cotidiano dos moradores. Além dessa abordagem, relacionada às políticas do governo e de natureza nacional, problemas da economia local tornavam ainda mais difícil a vida dos habitantes da Baixada Fluminense. Segundo Dona Lourdes, moradora do bairro Santo Antônio em Nova Iguaçu, reclamando do alto preço cobrado pelos produtos da cesta básica:

Os comerciantes geralmente não ajudam não. Eles vendem caro demais. Dizem que vendem caro porque vendem a crédito para receber no próximo mês. Se no próximo mês o quilo de arroz que eles vão comprar custa 20,00 cruzeiros eles não podem vender a 15,00 cruzeiros, que é o que custa hoje. Eles dizem que só podem vender no preço que vão pagar no mês que vem. (JORNAL DA BAIXADA, n.4, outubro de 1979, p. 5)

Segundo o Jornal, em sua quinta edição,

Na Baixada Fluminense, tudo é mais caro e de pior qualidade. São poucos os supermercados e lojas bem equipadas, que se concentram no centro das sedes dos municípios. Nos bairros, os moradores têm que depender de quitandas e biroscas que aumentam o preço dos produtos e são pouco sortidas. (JORNAL DA BAIXADA, n. 5, novembro de 1979, p. 45)

Ao descrever, nestas e em outras partes, a gravidade do custo de vida, a narrativa do Jornal aponta para a necessidade da ação coletiva para o enfrentamento do problema, indicando a luta através do Movimento Contra a Carestia, a formação de cooperativas de 
consumo e a reforma agrária como necessárias para a solução definitiva. O apoio da Diocese de Nova Iguaçu foi fundamental no incentivo à criação dessas cooperativas, de modo geral constituídas por participantes das Comunidades Eclesiais de Base (CEBs).

O Jornal divulgou a experiência de cooperativas de consumo, focalizando o grupo de compras constituído por dez famílias dos Bairros Fraternidade, Posse e Califórnia, também em Nova Iguaçu:

A ideia nasceu com participantes de um grupo de discussão do Evangelho, que tomou como ponto de partida grupos semelhantes formados em São Paulo e Belo Horizonte, com o objetivo de discutir a alta do custo de vida e tomar medidas práticas para a resolução do problema. Formado por assalariados (metalúrgicos, trabalhadores da construção civil, fumageiros, professores e funcionários públicos) o grupo fazia levantamento de preços e, a partir de uma caixinha organizada em comum, preparava listas de compras e buscava os locais com os melhores preços. (JORNAL DA BAIXADA, n.4, outubro de 1979, p. 5).

A queixa geral de todos os entrevistados remetia à falta de dinheiro, decorrente do arrocho salarial promovido pelo governo. Concluiu o Jornal:

Todos os trabalhadores sabem, por sua própria experiência, que os salários de hoje não compram a mesma coisa que compravam há cinco ou dez anos atrás. O salário, portanto, diminuiu, mesmo que hoje tenha números maiores. Patrões e governo dizem que não podem aumentar os salários, porque os preços sobem juntos. É claro, correto. Mas isto é verdade porque os patrões e o governo controlam os preços. Se os salários subissem, os lucros dos patrões diminuiriam. E aí que está o problema. Os patrões não querem que o lucro diminua. Então, aumentam os preços, e desvalorizam os salários. (JORNAL DA BAIXADA, n.4, outubro de 1979, p. 5).

Um grande espaço do Jornal foi dedicado às condições de trabalho (individuais e coletivas) e aos movimentos reivindicatórios em empresas e fábricas da região Isso se deu 
através de reportagens e de uma coluna especial, Chico Bé, dedicada a questões trabalhistas e sindicais.

Fui informado de que na KIBRAS (fábrica de basculantes, situada ali na Estrada São José, 1759, Caxias), os trabalhadores estão numa situação de arrepiar os cabelos. Serviço médico que é bom e necessário não existe. Existe, no entanto, uma enfermaria onde o pessoal é atendido por um trabalhador do almoxarifado, sem o menor conhecimento de higiene e muito menos de medicina [...] Ora, Kibras, tenha a santa paciência. Como se sabe, há sempre uma possibilidade de tétano quando alguém se fura com prego ou arrebite, e na tal enfermaria/almoxarifado não se toma injeção antitetânica. E o que é pior: não há nenhuma prevenção contra acidentes, nem mesmo óculos. Tô de olho, KIBRAS, tô de olho. (JORNAL DA BAIXADA, n.1, maio de 1979, p. 8)

Na mesma coluna, em outro número do Jornal:

Atenção metalúrgicos de Nova Iguaçu (Edson Passos, Mesquita, Belford Roxo, Santa Rita etc): todas as primeiras quartas-feiras de cada mês tem reunião na Delegacia Sindical do Sindicato dos Metalúrgicos de Nova Iguaçu, para endossar a luta e discutir os problemas da classe (JORNAL DA BAIXADA, n.2, junho de 1979, p. 8)

Na sexta edição eram narradas as agruras de uma funcionária de padaria de bairro, e criticada a inação de seus representantes sindicais:

Dona Delma, balconista da Padaria Estoril, no bairro Éden, de São João de Meriti, é testemunha das dificuldades que os comerciários sofrem na Baixada Fluminense. Ela trabalha oito horas por dia, todos os dias, domingos e feriados. Só tem folga de 15 em 15 dias. Assim mesmo, a folga vem pela metade. Para sair do trabalho meio expediente, Delma tem que estar na padaria às 6 horas da manhã e ficar lá até as 10 horas. [...] O Sindicato dos Comerciários de São João de Meriti, o representante da categoria de Delma e suas companheiras, nunca se manifestou sobre 
o assunto. Nenhum representante sindical jamais se preocupou com o trabalho na Padaria Estoril. (JORNAL DA BAIXADA, n.6, março de 1980, p. 8)

As diversas categorias profissionais presentes na Baixada Fluminense mereceram atenção nas reportagens e colunas do Jornal: ferroviários, professores, metalúrgicos, comerciários, com críticas à ação dos patrões e à omissão das diretorias sindicais.

Assumindo posição contrária ao Regime Militar e ao uso que este fazia das prerrogativas autoritárias presentes na Consolidação das Leis do Trabalho (CLT), o Jornal apoiou oposições sindicais e movimentos ocorridos à margem das direções oficiais. $O$ exemplo mais forte se deu na grande greve da Fábrica Nacional de Motores (FNM, à época pertencente ao conglomerado italiano FIAT), que mereceu edição extra do Jornal, noticiando o movimento e incentivando a participação de outros segmentos sociais em apoio aos trabalhadores parados.

O Jornal destacou o apoio dado por diversos segmentos sociais da Baixada Fluminense aos grevistas:

Duzentos lavradores, posseiros das terras que antes eram da Fábrica Nacional de Motores, hoje FIAT, em Xerém, estão apoiando a greve dos operários e contribuindo para o fundo de greve com produtos de suas lavouras. Eles também estão em luta pela posse de suas terras. $O$ Ministério da Fazenda, através do Instituto Nacional de Pesos e Medidas, está ameaçando despejar os posseiros que há mais de 20 anos vivem ali, cultivando suas terras.. (JORNAL DA BAIXADA, Edição Extra, agosto de 1979, p. 4).

A Igreja Católica também apoiou o movimento. Nesta mesma Edição Extra do Jornal, foi divulgada a "Carta à População" dos operários grevistas em 37 paróquias pertencentes à Arquidiocese de Nova Iguaçu. A leitura contou com a presença de representantes de várias categorias profissionais da Baixada Fluminense e de outras cidades do Rio de Janeiro.

Nas reportagens e colunas do Jornal, os exemplos de cobertura com esse teor político se sucedem, sempre tendo como tônica o apoio aos movimentos sociais, em suas várias frentes; os sindicatos, as lutas dos moradores pela casa própria e pela terra, as dificuldades decorrentes da inflação e do custo de vida, a oposição à política nacional e local. Mas as 
agruras da vida cotidiana sempre tiveram destaque. Os títulos e os conteúdos de várias matérias indicam essa direção. Por exemplo, na edição $n^{\circ} 4$ :

Santa Amélia bebe água de defunto. Santa Amélia - Nova Iguaçu -e é um bairro conhecido pelo alto índice de marginalidade: é grande o número de assaltos. [...] Mas as dificuldades não param aí. Grande parte do bairro não tem água canalizada, assim é obrigada a utilizar água de poço. Só que perto de Santa Amélia, num lugar conhecido como Solidão, tem um cemitério no alto do morro. A população que mora por ali se abastece de água de poço que talvez esteja contaminada. (JORNAL DA BAIXADA, n.4, outubro de 1979, p. 7).

Na edição $\mathrm{n}^{\circ} 6$ aparece a denúncia de outro dos problemas recorrentes na vida dos moradores da Baixada, as condições do transporte público:

Vida de gado, é o povo no roletão. Os roletões - esses instrumentos de humilhação e violência contra quem andam de ônibus - continuam sendo usados na Baixada Fluminense. A população protesta mas as autoridades encarregadas do assunto fazem vista grossa. (JORNAL DA BAIXADA, n.6, março de 1980, p. 8)

Merece atenção a ênfase dada pelo Jornal à situação da educação pública na Baixada Fluminense. Ao final da década de 1970 as políticas públicas promovidas pelos vários níveis do Estado não conseguiam atender às demandas crescentes da população: cita -se como exemplo que o fato de que a expansão da oferta das matrículas no ensino público estadual e municipal, particularmente o do então $1^{\circ}$ grau de ensino, não era mais suficiente para acompanhar o rápido aumento populacional ocorrido naquele período.

No caso dos municípios mais populosos da Baixada Fluminense em particular, tal estrangulamento ocorreu ao longo da década de 1970, produzindo uma rotina marcada por uma verdadeira mobilização para a guerra entre as famílias que possuíam filhos em idade escolar, nos períodos de matrícula. Uma cena comum no entorno das escolas públicas eram as longas filas de mães, pais e parentes (que não raramente ali estavam às vezes há dias, em regime de revezamento) à espera da abertura dos portões da escola para a matrícula de novos alunos. 
Sendo assim, a luta por acesso e permanência na escola na passagem entre as décadas de 1970 e 1980 pode ser caracterizada como uma verdadeira guerra de trincheiras combatida com afinco e persistência pelas mães e pais da região, politicamente organizados ou não. Muitos dos episódios desta luta foram narrados nas páginas do Jornal da Baixada.

Já em seu primeiro número, o Jornal da Baixada noticiava a mobilização de um grupo de mães cujos filhos encontravam-se sob a ameaça de serem obrigados a estudar no período noturno por decisão da Secretaria Estadual de Educação. Com o título "Calundu: mães venceram", o episódio em pauta era assim narrado:

No bairro do Calundu, município de Nova Iguaçu, a situação das crianças em idade escolar não é nada tranquila. As mães receberam comunicado da Escola Estadual Calundu na época de renovar matrícula, de que deveriam matricular seus filhos de 12 e 13 anos no supletivo primário, à noite - para dar vagas a outras crianças. Era uma ordem da Secretaria de Educação. As mães não aceitaram. Revoltadas com o fato de seus filhos, ainda crianças, serem obrigados a estudar de noite, decidiram agir. Foram à prefeitura de Nova Iguaçu protestar. A resposta foi que uma inspetora ia averiguar o problema lá mesmo na escola. No dia combinado para a visita da inspetora, as mães já aguardavam bem cedo na porta. Ela chegou, negou ter dado a ordem, dizendo que foi a professora responsável pela escola - não existe diretora no Calundu. $\mathrm{O}$ resultado: as crianças voltaram a estudar no horário antigo. (JORNAL DA BAIXADA, n. 1, maio de 1979, p. 6)

A forma como a autoridade responsável voltou atrás na sua decisão, eximindo-se de responsabilidade, indica indubitavelmente surpresa diante da resistência encontrada. Sinais claros de que o poder público não encontraria mais caminho tão fácil na gestão da educação sob estrito controle da burocracia do Estado e que nas próprias unidades escolares os dirigentes já não teriam suas decisões livres de contestação por parte da comunidade vinculada à escola.

Os exemplos de reportagens e colunas que enfatizavam a insatisfação e a revolta dos moradores se sucederiam, e esgotariam em muito o espaço deste artigo. Além disso, os títulos das reportagens remetem aos dos jornais populares de grande divulgação na região, que também se utilizavam de formas e expressões de ampla utilização pela população. Em que residiriam, neste sentido, as contribuições do Jornal da Baixada para a construção de referências alternativas para a imagem e a autoimagem da região? 
Em primeiro lugar, sua natureza francamente oposicionista, tanto ao Regime Militar, quanto ao "chaguismo" que dominava a política estadual e cujas ramificações estavam no poder em vários municípios da Baixada Fluminense. A crise econômica, o arrocho salarial, a insensibilidade com as necessidades da população, o autoritarismo e a ausência de espaços para participação popular eram criticados duramente em reportagens e editoriais. No editorial da Edição ${ }^{0}$ 2, lê-se por exemplo:

Queremos mais. O ano de 1979 tem sido marcado pelo surgimento de greves em quase todas as categorias profissionais, praticamente em todo o país. Essas mobilizações começaram já em fins de 78 e cabe a pergunta: porque tantas greves? Os governos militares de 64 pra cá, e as forças que os sustentam no poder, impuseram às classes trabalhadoras o regime do silêncio. Adoçaram a boca de setores da classe média com salários altos e a propaganda do país de grande potência, enquanto a grande massa de assalariados teve que "apertar o cinto" e fazer o milagre de se manter vivo. Não resta dúvida de que a causa primeira das greves são os baixos salários em contraposição ao alto custo de vida. (JORNAL DA BAIXADA, n.2, junho de 1979, p. 2).

$\mathrm{Na}$ coluna "Olho Vivo" (dedicada aos problemas dos moradores) publicada na Edição $\mathbf{n}^{0}$ 6, se critica duramente o prefeito de Nova Iguaçu:

Mais uma picaretagem do Queirós. Ruy Queirós, prefeito de Nova Iguaçu, está pensando que as audiências com os representantes dos bairros, às quintas-feiras, são um favor. É bom que o prefeito se lembre que este foi o compromisso assumido com os integrantes dos Movimentos dos Amigos dos Bairros (MAB), depois da Assembléia de 1978, na presença de centenas de pessoas. (JORNALDA BAIXADA, n.6, março de 1980, p. 2).

Vemos aí que o Jornal da Baixada assumia ele mesmo um papel de sujeito que reivindica. Dirigindo-se de forma direta às autoridades constituídas, particularmente os prefeitos dos municípios da região, o Jornal buscava dar maior alcance e maior peso político às demandas dos setores organizados da população da região, quando se tratava da cobrança de ações dos poderes públicos no sentido da resolução dos problemas vividos coletivamente pelos moradores. Dessa forma, a acima mencionada coluna "Olho Vivo" aparecia como o espaço 
particularmente dedicado à divulgação daquelas reivindicações e à cobrança de soluções por parte das autoridades mais diretamente responsáveis em cada município. É assim que no segundo número da publicação, por exemplo, a coluna citada denunciava a precariedade dos serviços de saúde na região:

O senhor Antonio Miranda, morador do bairro Vasco, Procurou há três meses o SAMDU (Serviço de Assistência Médica Domiciliar de Urgência), de Caxias, para se queixar de problemas de vista. Ele estava com a visão diminuindo, talvez por causa de seus 58 anos de idade. Não foi atendido no SAMDU e peregrinou pela Casa de Saúde Nossa Senhora Aparecida (onde permaneceu 22 dias), pela Casa de Saúde Santa Rita de Cássia (onde ficou 12 dias, até que seus parentes descobriram que a clínica não tinha oftalmologista). Tudo isso com guia de atendimento do SAMDU. O "seu" Antonio e seus parentes desistiram, e o paciente voltou pra casa. Mas logo o problema se agravou. Eles tiveram que voltar ao SAMDU, que encaminhou o senhor Antonio Miranda para a Casa de Saúde Santa Inês. Lá ele ficou 23 dias aguardando o atendimento. Para encurtar a história, os parentes do "seu" Antonio resolveram gastar o que não tinham e o levaram a um oftalmologista particular, cansado de correr atrás das casas de saúde que tem convênio com o INPS. $O$ médico diagnosticou falta de visão por causa de diabete, havendo necessidade imediata de cirurgia. Final da história: "seu" Antonio está completamente cego. (JORNAL DA BAIXADA, n.2, junho de 1979, p. 2).

Pode-se ver no estilo da denúncia uma das marcas da publicação em pauta: a escolha de uma história e de um "personagem" com o qual pudesse haver identificação imediata do leitor. Mas a narrativa do drama pessoal estava sempre a serviço da identificação com uma experiência coletiva de enfrentamento cotidiano do descaso das autoridades políticas e representantes do poder público.

Um segundo diferencial em relação aos periódicos de grande circulação ou aos jornais tradicionais está na aposta feita na organização coletiva, na mobilização e na articulação entre os vários setores da sociedade civil, ao invés das "queixas às autoridades" de indivíduos ou pequenos grupos de moradores, normalmente divulgadas na imprensa comercial, ou do apelo à intermediação de deputados e vereadores, muitas vezes para se conseguir direitos básicos, como a vaga do filho em uma escola pública ou a isenção do 
pagamento da taxa escolar, criando uma relação de dependência e troca de favores, tão comum à cultura política brasileira.

Neste sentido, o Jornal da Baixada buscava também chamar a atenção para a relação entre a situação de ausência de direitos sociais básicos que materializam a ideia de cidadania e a vigência de um regime político no país que continuava recorrendo ordinariamente à mecanismos repressivos e/ou intimidatórios. A ausência de direitos se casava nas páginas do Jornal à denúncia de tais práticas. Isso aconteceu, por exemplo, nos episódios de ataque ao posicionamento assumido pela diocese de Nova Iguaçu, tendo à frente D. Adriano Hypólito, em favor das lutas por direitos na Baixada Fluminense. Na coluna "Olho Vivo" da edição de novembro de 1979 podemos ver, sob o sugestivo título "Nem as igrejas eles respeitam mais", como o relato jornalístico se mostra também uma estratégia de pressão sobre os agentes da ditadura a fim de tentar defender preventivamente os que naquele momento se arriscavam no enfrentamento às forças direta ou indiretamente ligadas ao regime militar:

Duas igrejas de Nova Iguaçu - a Catedral de Nova Iguaçu a Igreja Santa Clara - amanheceram pichadas, no dia 9 de novembro, com ofensas a Dom Adriano Hypólito, o Arcebisbo Diocesano. Os pichadores acusaram o bispo de comunista, que as igrejas da Diocese eram sedes do Partido Comunista e outras ofensas impublicáveis. A Comissão de Justiça e Paz da Arquidiocese emitiu uma nota protestando contra a selvageria. Dom Adriano recebeu a solidariedade dos católicos que estão sob sua responsabilidade apostólica e de todos aqueles que, de outras religiões ou sem credo religioso, admiram e apóiam sua ação em favor dos pobres, maioria da população do município. É bom lembrar que Dom Adriano já foi vítima de uma ação típica de terrorismo da direita. Em 1976, ele foi sequestrado, ameaçado de morte, humilhado e abandonado $\mathrm{nu}$, o corpo pintado de vermelho, numa rua deserta. E nunca mais se teve nenhuma notícia de seus sequestradores. A polícia, tão pronta a desmantelar organizações classificadas por ela de "subversivas" e quando lhe convém - quadrilhas de bandidos, não conseguiu até hoje descobrir os autores da infâmia. Será que vai acontecer a mesma coisa agora? (JORNAL DA BAIXADA, n. 5, novembro de 1979, p. 2).

O Jornal da Baixada apostava numa nova cultura política que estava sendo forjada, naquele momento histórico, pelos movimentos sociais, tendo em comum a noção de que as condições de existência estavam no limite do suportável, de que a saída passava pelo 
reconhecimento de direitos até então negados e pela aposta na mobilização e na ação coletiva como formas de aquisição e fortalecimento da cidadania. (SADER, 1988, p. 261).

Desta forma, e aí se apresenta um terceiro diferencial do Jornal em relação a outros órgãos de imprensa e à visão que estes construíram sobre a Baixada Fluminense: ao mesmo tempo que noticiava e opinava sobre a região, seus moradores, suas agruras e reivindicações, promovendo a organização e ação coletiva, o Jornal da Baixada era, ele próprio, parte do movimento social. Sua estrutura, com um mínimo de profissionalização, e seu sistema de produção e distribuição eram baseados no trabalho voluntário de pessoas que, em sua maioria, participavam dos movimentos sociais da região.

\section{Conclusão}

A imagem da Baixada Fluminense, nas décadas de 1970 e 1980, espelhando os problemas da vida de seus moradores, e difundida a partir dos jornais que circulavam no Rio de Janeiro e regiões circunvizinhas, esteve sempre associada à violência cotidiana, à ação dos esquadrões da morte, à precária urbanização, à carência dos serviços públicos e aos problemas decorrentes da excessiva dependência econômica em relação à cidade do Rio de Janeiro, a qual em 15 de março de 1975, com a fusão entre os estados da Guanabara e Rio de Janeiro, tornou-se sede do governo fluminense.

No entanto, a região também conheceu a atuação de vigorosos movimentos sociais, que mobilizaram milhares de pessoas e deitaram raízes na cultura política local. A partir da segunda metade da década de 1980, indivíduos e correntes políticas que atuaram nesses movimentos, ou tiveram seu apoio, foram eleitos para o Parlamento e para Executivos municipais da região, disputando espaço com políticos oriundos de famílias tradicionais ou adeptos de práticas clientelistas. ${ }^{5}$

Ao longo dos anos, esses movimentos foram se legitimando diante da sociedade e do poder público. No entanto, ao mesmo tempo em que o Estado passava a reconhecê-los como instrumentos de representação e negociação, pode-se afirmar que as estruturas políticas oriundas dos movimentos sociais que tanto se fortaleceram no período aqui abordado também tenderam a incorporar práticas tradicionais da política brasileira.

5 Podemos enumerar, como exemplos: Lindberg Farias (PT), prefeito de Nova Iguaçu entre 2005-2010; Artur Messias (PT), deputado estadual e prefeito de Mesquita (2005-2012); José Cláudio da Silva (PDT), prefeito de São João de Meriti (19841988). Além desses, podem ser citados os deputados estaduais Carlos Correia (PDT)e Ernani Coelho (PT), eleitos em 1986, e Rosely Souza (PT) eleita em 1990. Todos os citados tiveram militância, apoio ou fortes vínculos com os movimentos sociais da Baixada Fluminense no período abordado neste artigo. 
Como em outras partes do Brasil, a Baixada Fluminense, a partir do retorno à democracia, no ano de 1985, vem experimentando, na política, na economia, na cultura e na vida social como um todo um jogo complexode transformações e permanências.

Não se busca, aqui, superestimar o peso social do Jornal da Baixada, produzido e distribuído a partir de redes militantes que, dadas as condições políticas da época e do lugar, viviam numa espécie de semiclandestinidade, atentas à possibilidade sempre presente de repressão por parte do Estado e de violência e desconfiança oriundas das forças políticas tradicionais da região. Sua tiragem era de cinco mil exemplares, e sua existência se limitou aos anos de 1979 e 1980.

No entanto, também não deve ser subestimada sua contribuição para a transformação de aspectos da cultura política da região. O Jornal da Baixada, em princípio, não era dirigido a militantes ou simpatizantes de determinadas correntes políticas, como ocorria com outros órgãos da imprensa alternativa. Sua abordagem dos problemas locais e a voz que dava aos habitantes da Baixada implicava a busca por um público diversificado, interessado na solução dos problemas concretos da vida cotidiana.

Além disso, sua publicação coincidiu com um momento especial da política brasileira, em que o enfraquecimento do Regime Militar, combinado com a crise econômica e a forte demanda dos movimentos sociais, alimentou a atuação de sujeitos políticos e sua ação coletiva.

O tempo do Jornal da Baixada é, ao mesmo tempo, próximo e distante. Próximo o suficiente para que, ainda hoje, diversas pessoas que participaram de sua produção e distribuição mantenham nas suas opções políticas grande parte das referências contidas no ideário de que o jornal foi portador.

Distante, no entanto, pela hoje evidente ingenuidade política fundada na crença de que uma nova sociedade poderia nascer dos movimentos que então cresciam rapidamente, englobavam e mobilizavam milhares de pessoas, e que pareciam conter o embrião de novas relações políticas e sociais. O tempo mostrou o quanto de antigo há no novo, o quanto ambos se engendram, as variáveis que se entrelaçam em meio à idéia binária, que à época parecia tão evidente, de que Estado e movimentos sociais se opõem, cabendo aos últimos o papel de ser o espaço de renovação das práticas sociais e políticas.

Mas, é claro, não se pode cair no anacronismo e buscar uma análise severa, fundada na confusa realidade do Brasil atual, onde conceitos políticos claramente distintos se diluíram nos vícios comuns de uma política que pouquíssimo representa as aspirações de seus cidadãos, mas onde se vive, pelo menos no campo formal, a possibilidade da discordância, comparando-a com o período em que o Jornal da Baixada existiu, onde as duras condições da 
existência política e social encontravam contrapartida na esperança que vinha da energia de forças que, por tantos anos, tinham sido contidas, e que despontavam com grande vigor.

\section{Referências}

ALVES, Maria H. Estado e oposição no Brasil (1964-1984). 4. ed. Petrópolis: Vozes, 1984.

BADARÓ, Marcelo. Novos e velhos sindicalismos no Rio de Janeiro (1955/1988). Rio de Janeiro: Vício de Leitura, 1988.

ENNE, Ana L. S. Imprensa e Baixada Fluminense: múltiplas representações. Ciberlegenda, Niterói, n. 14, 2004. Disponível em: < index.php/revista/article/download/222/118>. Acesso em: 27 jul. 2016.

GENTILI, Victor. A imprensa brasileira mudou bastante depois do AI-5... mas não como decorrência dele. In: MUNTEAL FILHO, Oswaldo; FREIXO, Adriano de; FREITAS, Jacqueline V. Tempo negro, temperatura sufocante: Estado e sociedade no Brasil do AI-5. Rio de Janeiro: Ed. PUC-Rio; Contraponto, 2008. p. 289-314.

MAINWARING, Scott. Igreja católica e política no Brasil (1916-1985). São Paulo: Brasiliense, 1989.

RIBEIRO, Adriana M. O Jornal da Baixada e o papel da imprensa alternativa na divulgação dos movimentos sociais na Baixada Fluminense (1979-1980). In: SIMPÓSIO NACIONAL DE HISTÓRIA - ANPUH, 26., 2011, São Paulo. Anais... São Paulo, 2011. Disponível em: <http://www.snh2011.anpuh.org/resources/anais/14/ 1313014045_ARQUIVO_textopublicado.anpuh.pdf $>$. Acesso em: 31 jul. 2016.

RIDENTI, Marcelo. O fantasma da revolução brasileira. 2. ed. São Paulo: Ed. Unesp, 2010.

SADER, Eder. Quando novos personagens entraram em cena: experiências e lutas dos trabalhadores da Grande São Paulo (1970-1980). São Paulo: Paz e Terra, 1988.

SILVA, Percival T. Origem e trajetória do movimento Amigos de Bairro em Nova Iguaçu (MAB) 1974-1992. 1993. Dissertação (Mestrado em Educação) - Fundação Getúlio Vargas, Rio de Janeiro, 1993. 


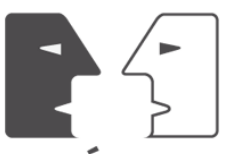

ANTÍTESES

Recebido em 06/11/2017

Aprovado em 29/06/2017 